\title{
Country Week: Bringing the City to the Country?
}

\section{Phil McManus and John Connell}

Recent decades have seen seemingly inexorable population decline in many parts of rural and regional Australia, despite local and national strategies to avert emerging economic and population imbalances (Country Shire Councils Association and Country Urban Councils Association Working Party; Pritchard and McManus). Since 2004 a novel initiative has sought to encourage new migration flows into rural Australia. Country Week, a three-day city fair operating in New South Wales and Queensland, involves rural and regional councils and other organisations publicising the advantages of rural areas and small towns and encouraging households to relocate from cities. Unlike most strategies for regional development, which are usually based on stimulating business activity, Country Week is a private sector initiative (albeit supported by governments), and is targeted at particular households. Country Week seeks to revitalise less obviously attractive regional areas as well as meeting and matching employment demands and opportunities in thriving regional areas. In so doing it has stimulated new ways of conceiving the country, challenged some perceptions of an urban-rural divide and created more flexible images of rural life.

Initiated by business groups from Armidale, in northern New South Wales, Country Week Expo has been held on four occasions in Sydney, and in Brisbane for the first time in 2007. The locations vary-Rosehill Gardens Racecourse in western Sydney contrasts with the inner-urban South Bank location in Brisbane. Entry is free to the public. The event is supported by significant political figures from across the political divide. Former Labor Premier of NSW, Morris Iemma, opened the 2006 Expo, which also featured a keynote speech by then Liberal Party Senator Amanda Vanstone, while the Expo has prominent National Party support. All parties support the notion of rural and regional growth. At all Expos local government authorities, government departments and businesses are represented among the exhibitors who pay to secure an exhibition space. There are also seminars on relevant topics for people who may be interested in moving from urban to country locations. As its 2008 website observes,

Country Week, the tree and sea change expo is your opportunity to find out about the virtues of living and working in country and regional Queensland or New South Wales. Country and regional areas offer professional and skilled trades people, as well as businesses, a wide 
variety of opportunities. Country Week is an easy, direct way to find out what is on offer. (Country Week Expo)

Country Week aims to attract disaffected urban residents to move to rural NSW or Queensland. The Expo is successful to the extent that it has continued for four years in NSW and has expanded into Queensland, although what constitutes success and quantifiable outcomes are hard to assess. Here we explore the theoretical context for this unique activity and seek to understand why some rural local authorities devote significant amounts of promotional time and financial resources to this annual event. In doing so, we shed light on perspectives held by urban residents who may be interested in re-locating to rural Australia, alongside the corresponding perspectives and goals of rural and regional councils, in order to identify some of the key concerns facing rural locations as they attempt to prosper in a highly urbanised eastern seaboard.

\section{Beyond Counter-Urbanisation, Rural Gentrification and Tree Change}

Much of the academic literature on rural change has focused either on the de-population of rural areas, or, particularly since the 1990s, on the opposite trend of 'counter-urbanisation' (Champion; Mitchell; Sant and Simons). The concept of counter-urbanisation, an umbrella term with many local variations, usually implies a relatively wealthy middle-class group withdrawing from urban settings to pursue a different lifestyle in a rural location. Much of this could also be described as rural gentrification, whether in Britain (Fielding; Milbourne, Revealing; Paquette and Domon) or Australia (Burnley and Murphy; Costello). In Australia, however, this concept tends to refer to permanent long-distance moves, usually described as 'sea-change', whereas in Britain it also incorporates commuting from urban peripheries. All of this literature is centred on assumptions of an urban-rural dichotomy, and therefore of class transformations in rural and regional areas. Milbourne calls for 'researchers of rural population change to engage more critically with discourses of mobilities, which involves them paying greater attention to the inter-connected empirical realities, representations and everyday practices of mobilities' (Milbourne, Revealing 382). While our research continues to focus 'on uni-directional flows of people to rural areas' (Milbourne, 'Re-populating' 384) it adds dimensions to counterurbanisation in seeing this as also an institutional strategy, involving centralised and localised place marketing strategies rather than simply a collection of individual decisions. And it is a strategy that is not solely directed at middle-class migrants promoting lifestyle, but targets 'housing stressed' people who may be prepared to vacate the expensive capital cities for a rural location (Bailey, 'Interview'). 
In Australia, most urban-rural migration has been characterised as 'sea-change' or, more recently, its inland version known as 'tree-change'. Such terms invoke images of mainly retired or semi-retired households moving to pleasant coastal and inland areas for lifestyle reasons, and labelled elsewhere as counter-urbanisation or rural gentrification (Burnley and Murphy; Sant and Simons). The terms are catchy - 'sea-change' being borrowed by the media-savvy demographer Bernard Salt from ABC's popular late-1990s drama series SeaChange (which of course had originally borrowed it from Shakespeare's The Tempest). The popularity of this trend is reflected in general statistics of people who are contemplating moving from Sydney to rural locations, which according to a Sydney Morning Herald opinion poll 'found one in five Sydneysiders are thinking of leaving because of high living costs, better job opportunities, or traffic congestion and overcrowding' (Creagh and Nixon 1). The popularity is also reflected in the emergence of a new magazine, Live the Dream: Sea and Tree Change Australia. Perpetuating the rural-urban dichotomy, a phenomenon that pervades much of the academic and popular literature, the editor's letter in the first edition of this magazine begins: 'The city and the bush: it seems there have always been two Australias' (Turner 2). Following Salt, who identified coastal non-metropolitan centres as the site of a third Australian culture, the magazine defines 'sea change' and 'tree change' as 'terms used to describe an Australian 'lifestyle swap" ('What is it?' 4). City life cannot be country life - the dichotomy is perpetuated.

By contrast, Country Week emphasises the diversity of potential urban-rural migration, and the blurring of any urban-rural divide: it is designed to attract younger entrants into the workforce, especially trades people and other skilled workers, by councils primarily from inland areas. Despite partially trading on similar images of rural idyll and lifestyle, the kind of population movement that inland councils seek is quite different from the earlier processes of rural gentrification and counter-urbanisation subsumed under the notion of 'sea-change'. The emphasis in Country Week on employment opportunities and housing prices is designed to attract a working population less able to afford the costs of big-city living. Low income, social service recipients are not targeted in the Country Week marketing. This raises questions about rural identity and the understanding of socio-economic status in rural migration, but also offers insights into why and how people may stay in rural areas despite the apparent presence of better opportunities in large cities (Hoggart). Country Week thus adds another distinctive dimension to counter-urbanisation by its focus on employment and housing issues, rather than simply lifestyle issues.

Amidst a global flight to the city in developing countries, long-distance commuting and counter-urbanisation have become increasingly common in more developed nations. Despite the existence of both trends, Australia remains distinctive as a developed nation where cities are growing at the expense of the 
country, and where there is significant but uneven rural population decline. Australia is therefore one of very few countries where there have been recent institutional attempts to 'sell' rural and regional areas to urban households. While Thomas Niedomysl has studied the impacts of place marketing by local authorities in Sweden, a rare example of a similar phenomenon, and has noted increased budgets for this activity given similar demographic changes such as an aging population, neither Sweden nor its regions had a centralised place marketing fair. Country Week thus provides an unusual example of shifting trends in rural place marketing (Niedomysl; Storey). While the concept of Country Week is unique, its expansion, evolution and the changing strategies of participating councils suggest that the concept of a centralised place-marketing fair with localised follow-up activities has potential to develop in many countries.

Country Week simultaneously involves cooperation and competition among representatives of different towns and regions. The concept underpinning the marketing strategy of Country Week, we argue, is the notion of 'countrymindedness'. There are four strands to countrymindedness, all of which are evident in the Country Week literature and at the annual Expos. These are an anti-urban bias, a pro-country bias, a concern about 'imbalance' and a desire to promote national development. While being careful not to denigrate cities, the 2007 message from the Country Week CEO, Peter Bailey, emphasised that in Sydney 'commuting times are getting longer, both partners are mostly working to service the mortgage and a rise in interest rates is a distinct possibility' (Bailey, 'Time' 2). In contrast, the country was said to offer people the opportunity of 'owning your own piece of paradise years before home ownership would be a reality in Sydney; the possibility of only one half of a partnership going out to work; and a healthier and safer environment for children' (Bailey, 'Time' 2). The inferences are that cities such as Sydney and Brisbane are expensive, generate national population imbalances that hamper regional economic growth, challenge a 'proper' family/work life balance, and are relatively unhealthy, even dangerous.

\section{Taking the Country to the City}

The methodology used for this research involved both quantitative and qualitative research techniques involving a questionnaire survey, formal in-depth interviews and general observations and discussions at the 2006 and 2007 Country Week Expos in Sydney, and the 2007 Country Week Expo in Queensland (Connell and McManus). This paper primarily analyses material from the 2006 Expo in Sydney. The questionnaire was designed to elicit the reasons for people's attendance at Country Week, identify the perceptions of these visitors about country towns and regions, and identify if and how Country Week Expo had influenced their perceptions. The questionnaire was administered over the three days of the Expo as an exit survey, so that the responses reflect what attendees had just experienced, rather than what they might hope to experience. 
Completing the questionnaire was voluntary. Boxes were provided for the completed questionnaires to ensure confidentiality. In 2006 in Sydney some 576 responses were received. Twelve in-depth semi-structured interviews were also conducted in 2006, with another six follow-up interviews conducted in 2007 in Sydney. The interviews, usually at least 45 minutes in duration, were conducted with local government representatives, and did not include other corporate, state government department or community service organisations that operate across a number of local government authorities.

Two groups of people were particularly interested in moving to rural areas: firstly, younger, often recently formed households, who were particularly concerned about the cost of housing and considered that country towns might offer a better lifestyle for bringing up children, and, secondly, older people whose children were now independent, whose parents did not require significant amounts of care, and who felt able to realise ambitions to move out of the city in the search for a better lifestyle. The first group emphasised economic issues; the second were less constrained.

Particular towns and regions were favoured for relocation (Table 1). There is no pre-Expo survey of visitors' preferred destinations, but it is very likely that respondents were influenced by the presence or absence of particular local governments, and by the displays, messages and general reception given by representatives of various local authorities. Younger and older visitors showed marked differences in relocation preferences: those in the 25-35 year old age category were interested in a variety of locations, although there was a preference for larger towns with diverse services (e.g., Armidale, Tamworth) and places that provided definite employment opportunities (e.g., Tumut, Oberon, Muswellbrook). People aged 50 years and over generally tended to want to move north, partly for climatic reasons. Larger towns, such as Armidale and Tamworth, were again popular. Moree had more appeal for older people than younger people, but less emphasis on employment meant that towns such as Muswellbrook and Tumut were not rated so highly by them. 
Table 1: Places to where the respondents in the 25-35 years old age category and the over 50 years old age category were thinking about relocating

Respondents who answered with general areas: (highest response only are shown)

25-35 years old age category

Over 50 years old age category

\begin{tabular}{l|l|l|l}
\hline Location & $\begin{array}{l}\text { Number of } \\
\text { Respondents }\end{array}$ & Location & $\begin{array}{l}\text { Number of } \\
\text { Respondents }\end{array}$ \\
\hline Coastal Regions & 2 & Central West & 3 \\
Far North Coast & 2 & Mid North Coast & 4 \\
Mid North Coast & 2 & North Coast & 4 \\
North Coast & 2 & North West NSW & 3 \\
South Coast & 2 & Northern NSW & 5 \\
Southern Highlands & 3 & South Coast & 2 \\
South of Sydney & 2 & & \\
\hline
\end{tabular}

Respondents who answered with specific areas and towns (highest responses only are shown in alphabetical order)

25-35 years old age category

Over 50 years old age category

\begin{tabular}{l|l|l|l}
\hline Location & $\begin{array}{l}\text { Number of } \\
\text { Respondents }\end{array}$ & Location & $\begin{array}{l}\text { Number of } \\
\text { Respondents }\end{array}$ \\
\hline Albury & 2 & Armidale & 8 \\
Armidale & 11 & Boorowa & 3 \\
Ballina & 2 & Canberra & 4 \\
Canberra & 2 & Cootamundra & 5 \\
Cooma & 2 & Crookwell & 2 \\
Cootamundra & 5 & Dubbo & 2 \\
Forbes & 4 & Forbes & 4 \\
Grenfell & 3 & Grafton & 2 \\
Hunter Valley & 2 & Grenfell & 2 \\
Inverell & 3 & Inverell & 2 \\
Mudgee & 2 & Moree & 5 \\
Muswellbrook & 3 & Mudgee & 4 \\
Northern Rivers & 2 & Oberon & 5 \\
Oberon & 4 & Orange & 9 \\
Orange & 2 & Tamworth & 2 \\
Parkes & 2 & Upper Lachlan & 2 \\
Port Macquarie & Wauchope & 2 \\
Snowy Mts & 6 & Yamba & \\
Tamworth & 6 & & \\
Tumut & 5 & & \\
Yass & 6 & & \\
\hline & 2 & & \\
\hline
\end{tabular}

A number of conclusions can be drawn from people's aspirations. Firstly, most people are interested in moving northwards from Sydney, and there is no reason for stopping at the NSW border. Secondly, larger towns with larger, more diverse displays in Country Week, such as Armidale and Tamworth, are perceived as being relatively attractive. Smaller towns with smaller exhibitions, some like Warialda, virtually unknown in Sydney, are perceived less favourably. In large part this is simply because visitors already knew something about or had at least heard of larger towns. Having a well-known Country Music Festival (Tamworth), 
or even a Celtic Festival and the Country Week stall decked in tartan (Glen Innes), were major advantages. Thirdly, a large number of people wished to move to places that were not represented at Country Week, notably inland centres such as Bathurst, Mudgee, the Southern Highlands and Orange, and all parts of the north and south coast. Clearly some places were already being considered as possible sites for re-location by people prior to their attendance at Country Week, and the Expo, for these people, is likely to reinforce or clarify earlier perceptions. Fourthly, there was a distinct preference for places that were not too far from Sydney, such as Oberon, the nearest place to Sydney represented at the Expo, while distance was a real disadvantage for such small towns as Warialda and Glen Innes. People sought to move 'out of town but not out of touch'. On the other hand, towns that might otherwise seem relatively disadvantaged but mounted impressive displays, such as Moree (voted the best display by other stallholders in both the 2006 and 2007 Expos), generated considerable interest.

Many potential movers had pre-existing ideas about where they wanted to move and what qualities they were looking for, views shaped by factors other than Country Week. Unsurprisingly these combined a pleasant lifestyle, often seen as being linked to coastal residence, and the continuation of a reasonable number of amenities and services. Country Week is therefore crucial in that it is one of very few opportunities for inland towns to demonstrate that they too have many such valuable qualities and to move people away from perceptions that 'rural' is a negative phenomenon, only associated with what was described to us by Peter Bailey as 'droughts and dead sheep in the dam'.

Many potential movers go through a series of 'stages', which can be loosely described as beginning with being 'interested in learning more' through 'considering moving' to 'have decided to move'. In some cases these stages coincide with successive annual Country Week events. Several people were visiting for the second or third time, often supplemented by visits to one or more towns (sometimes for open days specifically designed as follow-up events). Stages exist because the Expo attracts many first time visitors with relatively little knowledge of country areas, and none with experience across the range of places promoted. Friendliness encouraged return visits; many of those remarked 'we shall be back next year'. One attendee said 'I found each stall that I went to very interesting and informative. I found the people helpful and encouraging about the different resources found in the areas they live in. I will be back next year and I am grateful for the assistance.' Another stated that 'there will be questions in the future. I first have to read the brochures and contact relevant councils and real estate agents. I estimate this will take me through to the end of September'. The Australian tradition of collecting showbags filled with hopefully fascinating brochures, free pens, fridge magnets and so on, ensured a lengthy process. 
Continuity in Country Week, and the consistent presence of individual towns over a period of time, was thus essential. Most visitors were challenged by the number of places - 'over eighty regional towns, cities and groups are represented at Country Week' ('Country Week' 3) - and to some extent the similarity of each place's marketing strategies. They therefore struggled to differentiate between towns and regions and realised that more time and knowledge (and probably visits) were required to make reasonable assessments. As one put it quite simply: 'I just don't know where to go to'. Others recognised the need to visit a range of places: 'will there be an abattoir in the main street that they forgot to mention?' While this makes evaluation of the success of Country Week almost impossible, one spin-off has emerged. Potential places for relocation become tourist destinations for potential residents. At its most extreme, one mother of two preschool children confided: 'We like to visit a different place every year so that the children will know their country and we will know where to move to when they are old enough to leave home'.

Overall, housing and employment were the main factors that potential migrants sought outside Sydney, and Sydney's expensive housing market was a particular incentive to migration. While most visitors mentioned quality of life as the key attraction to a potential move, this was underpinned by the necessity for housing and usually employment. Urban congestion and crime were rarely mentioned and those who were most interested in moving tended to be either too young or too old to worry unduly about education and sporting facilities. Potential migrants were more discouraged by the costs of urban residence, the main factor that had drawn them to the Expo, than they were lured by some notion of country lifestyles.

\section{The Perspectives of Country Towns and Shires}

Not all regional councils were represented at Country Week 2006 and 2007, and numbers have fallen since 2005. Coastal councils such as Nambucca and Coffs Harbour no longer attend because they have little trouble attracting people to that part of the coast, especially as the baby boom generation reaches retirement age. These locations now face some degree of congestion, and issues of service provision for their existing aging populations. Hence they have no wish to attract even more residents. However it is not only coastal councils that have dropped out of Country Week. Between 2005 and 2006 most of the councils from far western NSW (such as Wagga Wagga, Deniliquin and Bourke) dropped out as did several from the Hunter Valley, mostly because they felt that the results did not justify the costs of their participation, although some councils such as Bourke continue to advertise in the Expo brochure. The councils who have regularly attended thus represent a broad band through central NSW, excluding the far west and the coast. 
Most local authorities emphasised a range of available jobs in country towns (including skilled, unskilled and professional employment and business opportunities), as did organisations representing corrective services, education and so on, but those councils that had a specific list of particular vacancies available immediately had the greatest success in attracting interest, at least from visitors for whom employment was particularly important. This promotion of specific jobs rather than general employment was one productive marketing trend. One council had what appeared to be a particularly direct and thus useful message with a poster stating 'If You Are a Plumber We Need You'. A visiting dentist was strongly courted by several councils.

Councils attend Country Week for many reasons. The decision is not taken lightly, because it involves a significant cost to rent a stall and because the costs of transport, accommodation, display preparation and the opportunity cost (and overtime) of the labour must be accounted for. To be really effective, the costs might also include producing a special issue of the local newspaper, preparation work (including working with local businesses, including estate and travel agents and also schools, to identify needs and opportunities) and follow-up work (contacting visitors, organising open days and visits, and so on). Some of the councils that could benefit most from being present probably could not afford to attend. Councils usually initially attended the event to observe, and to decide if the investment in time and money was likely to be worthwhile, while internal politics and local financial considerations were a significant factor in whether they would participate. Once again the difficulty in assessing the measurable outcome of participation was problematic for many councils.

There were local benefits. In some cases Country Week was seen as a way of removing people from their communication 'silos' and engaging in a shared, positive activity that would enhance teamwork and yield beneficial results outside of the Expo. This was partly to do with the focus outwards (promoting rural communities in Sydney) in ways that improved internal cohesion. For one council: 'If you are going to solve some of the tough inward problems it is very important to get people to focus outwards. They start to think of ideas, to get recharged, and this feeds back into the community.' Some councils actively learned from others how they might develop more effective strategies and presentations to encourage migration, and were carefully monitoring the benefits of participation. Many stated that the decision to attend was conditional on how well Country Week Expo 2006 went. For example: 'the crowd is down ... If we get a few nibbles from this year I think we'll be tempted to come back, but if we don't get anything from this year I think we'll be reassessing our commitment'.

Country Week also promotes the town or region to its existing residents, including both information and a sense of pride, action and achievement. Many 
local newspapers ran stories, or produced a special Country Week Expo supplement, that highlighted both what was happening at Country Week and their own previous 'success stories'. In some of the larger towns the media ran both 'before' and 'after' stories.

The availability of competing events or processes, and the inability to engage in all of these activities required councils to make choices about their priorities. In 2006 the Inland Cities Alliance emerged, with aims that appeared to coincide with those of Country Week, though with a more targeted plan to attract residents of Sydney to larger regional centres. Queensland put on its own 2006 Expo at the Sydney Olympic site, barely five kilometres away from the NSW Country Week event. Fission of this kind, and the emergence of alternative events and sources of information, could weaken the significance and influence of Country Week, but currently Country Week still offers something to rural councils - a point of contact with urbanites who for the most part are genuinely interested in relocating.

Simply being there was seen as important by councils. An exhibitor from a relatively small town was sceptical about the benefits: 'We miss out to the big, nearby places so it's hard to say what we got out of it last year - just tradespeople who knew we were here and came to talk to us - but we have to be here-we have to have our image in the market place'. Yet not all councils, presumably including those who dropped out between 2005 and 2006, accept this need to be in the marketplace at some cost. A more effective evaluation of what being 'in the marketplace' actually means, what the real benefits of taking part in Country Week are, and then how a more positive message about these benefits can be diffused to those who have participated and might participate subsequently, continues to evolve.

The more successful councils in terms of population growth saw Country Week as part of a bigger commitment to marketing their town. This in turn influenced their expectations about what could be achieved from Country Week, and was very likely to influence their assessment of the success or otherwise of the event for their council. For some the Country Week Expo was their main marketing tool, and other events such as follow-up tours were closely linked to Country Week. Country Week was seen as a way of making contact with interested people, and the follow-up as being the important work that would not have been possible without the Expo's 'gateway':

I think the idea is great and coming down here is a better idea than holding an open weekend when we try and say everyone come up here, because we don't have the contacts. We don't know who the people are that are interested. We need to contact them in this environment and then invite them up. (Exhibitor 6) 
The importance of the event also varied depending upon the involvement of local businesses in particular towns. Real estate agents have increasingly found Country Week Expo to be particularly important for them. Indeed a number of participants were financially supported by local businesses, including real estate agents. In other instances the importance was related to timing. If there was a particular skills shortage, an impending boom, or a threat to the continuation of services, then Country Week assumed greater significance as a means to address a particular issue.

One important perception of Country Week Expo is that it facilitates the presence of genuine inquiries from prospective migrants, rather than 'tyre kickers'. Many participants were evaluating the success of their Country Week investment on the quality, rather than the quantity, of contacts made. The dilemma for Country Week is how to maintain the perception from councils that people who attend Country Week are genuinely interested in relocating from the city to the country. One response here has been to increasingly promote real estate and employment opportunities, whilst not diminishing the ongoing promotion of lifestyle.

\section{Conclusion: Taking the City to the Country}

Country Week Expo is an innovative engagement between urban residents and rural communities. It crosses many perceptual divides between city and country, and encourages direct contact between these groups of people rather than engagement mediated by newspapers, radio and television. The numbers attending the Expo offer clear evidence of the continued interest in moving to rural areas, and neither tree-change nor sea-change are losing momentum. But Country Week offers a new strand in counter-urbanisation, by the deliberate search for migrants who are also workers, lured by lower house prices and employment opportunities rather than by a more intangible 'lifestyle' attraction. Such migrants are less likely to be middle class. Gentrification has been turned on its head.

The decision for urban-dwellers to relocate to the country appears as a staged process, summed up in the 2007 Country Week brochure as from 'Country Week to country life'. Return visits to Country Week, and follow-up visits to country towns to attend festivals and become more familiar with a potential new home, are important elements of the decision-making process. While Country Week Expo is only a three-day annual event, it is at the core of place-marketing campaigns for many country towns because it brings selected residents of rural locations together with prospective urban migrants who are at various stages in the process of relocation decision-making. Without Country Week it is possible that ne'er the twain shall meet.

Council participation at Country Week Expo requires a significant commitment of resources, plus important preparation and follow-up work, in order to be 
successful. It is worthwhile to many councils for a diversity of reasons, but importantly because putting themselves on the map of urban consciousness guarantees at least minimal interest and possible tourist outcomes. At the same time the scale of the event demands both cooperation (unusually perhaps between the private sector and the public sector) and, as far as possible, a distinct construction of 'country' as a highly attractive and viable location to live.

Most Expo visitors are genuinely considering moving away from the city, not necessarily out of any dislike for urban areas but because of housing costs. Appropriate employment for most is essential. Equally there is no real 'countrymindedness': most potential migrants simply seek adequate services and amenities - health, education and shopping. Ironically this means that the larger country towns are most attractive because of the range of possibilities they offer, and, rather than promoting the country and portraying large cities negatively as one might expect, councils such as Tamworth are encouraging migration using the slogan 'city style - country heart'. While smaller, more remote towns are benefiting from Country Week by the retention of services through small gains in population (or maintaining a stable population), and geographically specific resource booms are being matched with suitable employees, it also appears that new migrants are boosting the places that are most like cities, especially those closest to 'home': they are taking the city to the country.

Phil McManus is a senior lecturer in the School of Geosciences at The University of Sydney. He is the co-editor of Land of Discontent: The Dynamics of Change in Rural and Regional Australia (UNSW Press, 2000) and the author of Vortex Cities to Sustainable Cities: Australia's Urban Challenge (UNSW Press, 2005).

John Connell is Professor of Human Geography in the School of Geosciences at the University of Sydney. He is interested in development issues in island states and in the role of culture in development. He has recently edited two books, The International Migration of Health Workers (Routledge: New York, 2008) and, with Barbara Rugendyke, Tourism at the Grassroots. Villagers and Visitors in the Asia-Pacific (Routledge: London, 2008).

\section{Works Cited}

Aitkin, Don. "'Countrymindedness": The Spread of an Idea.' Australian Cultural History 4 (1985): 34-41.

Bailey, Peter. 'Interview with Deborah Cameron,' 702 ABC Radio 3 March. 2008.

- 'Time For a Change?' Live the Dream: Live, Work and Invest in Regional NSW, Country Week, 2007: 2. 
Burnley, Ian and Peter Murphy. Sea Change: Movement from Metropolitan to Arcadian Australia. Sydney: UNSW Press, 2004.

Champion, Tony. 'Studying Counterurbanisation and the Rural Population Turnaround.' Migration into Rural Areas: Theories and Issues. Eds. Paul Boyle and Keith Halfacree. Chichester: John Wiley and Sons, 1998. 21-40.

Connell, John and Phil McManus. Rural Revival? Place Marketing and Migration. Country Week in Australia. Aldershot: Ashgate, 2009.

Costello, Lauren. 'Going Bush: The Implications of Urban-Rural Migration.' Geographical Research 45:1 (2007): 85-94.

Country Shire Councils Association and Country Urban Councils Association Working Party. Country Towns: A Future or Funeral? Report of a Joint Country Shire Councils Association and Country Urban Councils Association Working Party. Bunbury: Country Shire Councils Association and Country Urban Councils Association Working Party, 1990.

'Country Week-About Grenfell.' Grenfell Record 9 Aug. 2007: 3.

Country Week Expo. 5 Mar. 2008. < http://www.countryweek.com.au/>.

Creagh, Sunanda and Sherrill Nixon. 'The Great Sydney Exodus.' Sydney Morning Herald 3 Mar. 2008, 1.

Exhibitor 6, Country Week Expo, Sydney interviews. 2006.

Fielding, Tony. 'Counterurbanisation and Social Class.' Migration into Rural Areas: Theories and Issues. Ed. Paul Boyle and Keith Halfacree.

Chichester: John Wiley and Sons, 1998. 41-60.

Hoggart, Keith. 'The Diluted Working Classes of England and Wales.' Journal of Rural Studies 23 (2007): 305-317.

Milbourne, Paul. 'Re-Populating Rural Studies: Migrations, Movements and Mobilities.' Journal of Rural Studies 23 (2007): 381-386.

— - ed. Revealing Rural Others: Representation, Power and Identity in the British Countryside. London: Pinter, 1997.

Mitchell, Clare. 'Making Sense of Counterurbanisation.' Journal of Rural Studies 20 (2004): 15-34.

Niedomsyl, Thomas. 'Evaluating the Effects of Place Marketing Campaigns on Inter-Regional Migration in Sweden.' Environment and Planning A 36 (2004): 1991-2009.

Paquette, Sylvain and Gerald Domon. 'Changing Ruralities, Changing Landscapes: Exploring Social Recomposition Using a Multi-Scale Approach.' Journal of Rural Studies 19 (2004): 425-444. 
Pritchard, Bill and Phil McManus. Land of Discontent: The Dynamics of Change in Rural and Regional Australia. Sydney: UNSW Press, 2000.

Salt, Bernard. The Big Shift: Welcome to the Third Australian Culture. Melbourne: Hardie Grant Books, 2001.

Sant, Morgan and Peter Simons. 'Counterurbanisation and Coastal Development in New South Wales.' Geoforum 24 (1993): 291-306.

Storey, David. 'A Sense of Place: Rural Development, Tourism and Place Promotion in the Republic of Ireland.' Geographies of Rural Cultures and Societies. Ed. Lewis Holloway and Moya Kneafsey. Aldershot: Ashgate, 2004. 197-213.

Turner, Graham. 'Editor's Letter.' Live the Dream: Sea and Tree Change Australia 1 (2008): 2.

'What is it?' Live the Dream: Sea and Tree Change Australia 1 (2008): 8. 